\title{
RELACIONAMENTOS COLABORATIVOS EM REDES DE SUPRIMENTOS
}

\section{RESUMO}

Algumas das tendências recentes relacionadas às práticas de gerenciamento da cadeia de suprimentos como outsourcing estratégico, diferenciação e especialização de funções, arranjos colaborativos, ampliação e incremento dos níveis de serviços logísticos - estão sendo impulsionadas por empresas interessadas em otimizar a coordenação logística em um cenário de crescente customização e complexidade no mundo dos negócios. As estratégias de segmentação de fornecedores e clientes no contexto da cadeia de suprimentos representam uma oportunidade para estimular ambientes colaborativos e incrementar, assim, a qualidade dos serviços e produtos oferecidos aos clientes finais, bem como reduzir os custos produtivos e logísticos. Neste artigo, defende-se a idéia de que as estratégias de segmentação em determinados regimes (parceria e quase-mercado) definem a infra-estrutura relacional adequada para suportar práticas colaborativas nas transações entre os agentes econômicos e, conseqüentemente, favorecer os padrões de competitividade de empresas e cadeias de suprimento.

\section{Marcelo Bronzo \\ CEPEAD/CAD/UFMG}

\begin{abstract}
Some of the most recent tendencies observed in supply chain management practices - such as strategic outsourcing, differentiation, specialisation and collaborative arrangements - are being driven by firms interested in optimising logistic coordination in a scenario of increasing customisation and complexity in the business world. The supplier and client strategic segmentation processes in a SCM context represent an opportunity to enhance the creation of collaborative environments that may foster the quality of services and products offered to final customers along with a reduction in production and logistical costs. This article, therefore, highlights the fact that segmentation strategies in certain partnership relations and quasi-market relationships can perhaps bring about a better infrastructure relationship to sustain collaborative practices between economic agents and, consequently, favour sustained competitiveness in the production chain.
\end{abstract}

PALAVRAS-CHAVE Gestão da cadeia de suprimentos, estratégias de segmentação, integração de processos logísticos, competitividade, economias associativas.

KEY WORDS Supply chain management, segmentation strategies, logistics integrated processes, competitiveness, associative economies. 


\section{INTRODUÇÃo}

Nos últimos anos, um volume expressivo de pesquisas tem se dedicado à investigação dos antecedentes, da estrutura e da função do relacionamento interorganizacional, dando especial atenção aos resultados das alianças estratégicas em estruturas de relacionamento entre empresas fornecedoras e clientes. Os resultados desse imenso esforço científico são teorizações mais abrangentes, robustas e úteis ao avanço das práticas gerenciais e dos estudos empíricos nesse campo do conhecimento, como atestam os trabalhos de Möllering (2003), Nohria (1992), Kogut, Shan e Walker (1992), Koza e Lewin (1998), entre outros.

As pesquisas desenvolvidas sobre o tema das alianças estratégicas incluem estudos proeminentes a respeito: a) dos antecedentes, da estrutura e da funcionalidade das alianças nos contextos internacionais (Sturgeon, 2000; Contractor e Lorange, 1988; Reuer e Miller, 1997; Anderson e Gatignon, 1986); b) dos aspectos relacionados ao maior ou menor incentivo para a concretização das alianças, tais como o oportunismo, a confiança e os contratos (Gulati, 1998; Ring, 1997); c) da escolha das alianças como mecanismo alternativo de governança, comparativamente ao mercado e à hierarquia (Kogut, 1988; Hennart, 1988); d) das variáveis associadas ao sucesso e ao fracasso das alianças entre empresas (Doz, 1996; Parkhe, 1993); e, por fim, e) das relações interorganizacionais e das redes de empresas como unidades de análise e classes particulares de fenômeno a serem pesquisadas no campo das ciências gerenciais e administrativas (Astley, 1984; Di Maggio e Powell, 1983; Buckley e Casson, 1988).

A integração efetiva dos processos logísticos entre fornecedores e clientes na cadeia de valor envolve a formatação e o gerenciamento de alianças estratégicas entre as empresas, gerando assim o aumento da "densidade" do vínculo de relacionamento entre os agentes, em que complexos processos intra e interorganizacionais serão integrados (Dubois e Hakansson, 1997; Ebers e Jarillo, 1998; Cooke e Morgan, 1998).

Este trabalho tem como objetivo apresentar uma discussão teórica sobre o problema da coordenação dos processos logísticos e dos recursos tangíveis e intangíveis na cadeia de valor.

O artigo está estruturado em dois grandes blocos teóricos, relativos ao objetivo principal do trabalho: na primeira seção, são apresentadas considerações preliminares a respeito da logística e da coordenação dos processos logísticos nas empresas, sinalizando a im- portância das novas práticas para o bom uso dos recursos críticos disponíveis e para o realinhamento dos objetivos estratégicos de empresas fornecedoras e clientes em metas comuns, orientadas para a criação de valor a clientes intermediários e finais.

Em um segundo momento, o artigo faz referência aos diferentes regimes de segmentação de fornecedores e sinaliza quais estratégias de segmentação seriam mais adequadas à filosofia da gestão integrada da cadeia de suprimentos quando se trata de considerar os processos de suprimento e de inovação entre as empresas. Também nessa segunda parte são apresentados conceitos centrais relativos aos regimes de segmentação de clientes, defendendo-se a idéia de uma gestão executiva da logística mais atenta às diferenças de rentabilidade de clientes e de suas demandas em termos de serviços. O processo de segmentação de clientes é abordado a partir de uma perspectiva teórica que releva a função executiva do "gerente de contas especiais" (key account manager), apresentando-a como uma atividade fundamental para a boa coordenação dos processos logísticos a jusante nas cadeias de valor. Seguem, ao final, algumas notas conclusivas sobre os assuntos tratados no artigo.

\section{A COORDENACÃO DE RECURSOS LOGÍSTICOS NA CADEIA DE VALOR}

A integração dos processos e das atividades circunscritas às logísticas de suprimentos, ao apoio à produção e à logística de distribuição é um pré-requisito importante para a gestão de custos e serviços no exercício operacional da função, geralmente com o propósito de aumentar a competitividade sustentada das empresas e gerenciar adequadamente o problema do valor para os clientes finais em uma cadeia produtiva. O projeto ou o reprojeto da rede logística quase sempre envolvem atividades circunscritas a esses ciclos de suprimento, produção e distribuição, como também o alinhamento sistêmico das decisões empresariais relativas a compras, estoque, transporte, armazenagem e processamento de pedidos aos clientes (Christopher, 1997; Novaes, 2001; Bowersox et al., 1992; Kobayashi, 2000; Fleury, 2000).

Em um trabalho recente, Kopczak e Johnson (2003) exploraram aspectos importantes relativos à gestão integrada dos processos logísticos e aos efeitos de tal gestão sobre a competitividade empresarial e sobre a criação de valor. Segundo os autores, mudanças em 
curso estariam forçando as empresas a reexaminar sua visão do negócio e a redefinir em quais processos focalizar seus recursos e competências, questão esta extremamente crítica para a logística por conta da intensidade de investimentos em ativos específicos e por conta da necessária utilização de recursos tangíveis e intangíveis nas transações comerciais.

Para Kopczak e Johnson (2003), a filosofia e a prática da gestão integrada da cadeia de suprimentos estão relacionadas a seis grandes conjuntos de mudanças no pensamento empresarial. As melhores práticas logísticas estariam sendo reorientadas a um objetivo claro de aquisição de vantagens competitivas a partir de uma melhor coordenação das funções da logística empresarial, bem como a partir de uma maior integração da função logística com outras áreas de decisão nas empresas, como finanças, marketing e engenharia de processos e produto.

As mudanças em curso, apontadas por Kopczak e Johnson (2003), poderiam ser assim resumidas: 1) a integração de processos internos e externos visando ao alinhamento de objetivos e tomadas de decisões com fornecedores, clientes e agentes facilitadores (por exemplo, um operador logístico) participantes da rede de suprimentos; 2) a minimização dos custos de produção e distribuição, adequando-se melhor as exigências de volumes e tipos de produtos entre as instâncias de oferta e consumo, paralelamente à redução dos custos relacionados aos elementos de precaução no sistema logístico (capacidade excedente, estoques de segurança e precificação defensiva, entre outros); 3) a busca pela antecipação do ponto de penetração do pedido, a partir da coleta e do tratamento de informações atualizadas sobre a demanda. A partir de tal procedimento, o que as empresas parecem querer evitar é o efeito chicote, em que, por conta da baixa integração dos fluxos informacionais sobre a demanda, pequenas variações na demanda final provocam amplificações indesejadas a montante na cadeia de suprimentos; 4) a integração dos processos de inovação com fornecedores e clientes, antecipando-se a colaboração desses agentes nas atividades de P\&D das empresas; 5) a integração das funções e atividades do composto de marketing e do composto logístico, por meio da integração entre decisões de produto, preço, promoção e canais de marketing às decisões logísticas relacionadas a compras, estoque, transporte, armazenagem e processamento de pedidos; 6) a customização de produtos e de serviços logísticos a partir do uso sistemático das novas tecnologias de informação, permitindo às empresas geren- ciar melhor seus recursos de produção e logísticos e atuar proativamente no que se refere à elasticidade da demanda e às modificações desejadas pelos mercados em termos de especificações de produtos.

A partir da perspectiva sistêmica defendida por Kopczak e Johnson (2003), entende-se que uma coordenação logística ruim poderia ser identificada quando, por exemplo, os setores de vendas e de distribuição resolvem adotar uma gestão mais permissiva de estoques de produtos finais, enquanto o que a produção objetiva é reduzir o nível de inventários no sistema, alegando que eles deprimem as margens e trazem piores resultados para a performance operacional da empresa. O problema aqui está em equacionar devidamente o fluxo de recursos e de informações que percorrem toda a cadeia de suprimentos: quanto mais reconhecidos e monitorados forem esses fluxos, menor será a necessidade de estoques de segurança para atender à demanda e às necessidades da produção (Ferrozi, Hammond e Shapiro, 1993; Christopher, 1997). Em linhas gerais, isso significa que, quanto menos informação possui a empresa, ou quanto mais pobres mostram-se os seus fluxos de informação com outras empresas, maior será a necessidade de elementos de precaução (estoques, fundamentalmente) para atender às flutuações na demanda, o que traz impactos diretos nas margens de lucros da firma.

Entre os meios disponíveis para buscar-se incrementar o potencial de customização com fornecedores, clientes e a melhoria da coordenação logística em cadeias de suprimento, estão as práticas de segmentação. A segmentação estratégica de fornecedores e de clientes podem potencializar o interesse dos agentes econômicos pela especialização em certas atividades e processos produtivos e logísticos em determinado campo interorganizacional, e, naturalmente, essa maior especialização pode vir a gerar benefícios superiores (valor) aos clientes finais da cadeia. Essas questões serão exploradas a seguir.

\section{ESTRATÉGIAS DE SEGMENTAÇÃO DE FORNECEDORES E DE CLIENTES NA CADEIA DE VALOR}

\section{Segmentação de fornecedores nos processos de produção de bens e serviços}

Qualquer empresa que tenha buscado a terceirização para reduzir custos ou obter acesso a recursos externos complementares passa a ter de coordenar melhor 
seus processos de outsourcing e a monitorar de forma mais cuidadosa a gestão de seus vínculos de relacionamento com fornecedores e clientes (Brown e Hendry, 1998).

Apesar das diferentes denominações, pode-se afirmar que existem três tipos possíveis de segmentação de fornecedores para as políticas de suprimento: relações do tipo arm's length (mercado), de parceria e de quase-mercado (Dyer, 1997; Dyer, Cho e Chu, 1998).

A taxonomia para esses diferentes regimes de segmentação é coerente, em certos pontos, com a abordagem proposta por Hall e Soskice (2001), ao discutirem os problemas de coordenação das firmas em diferentes experiências de países capitalistas. Para esses autores, determinados arranjos econômicos e políticos de regiões e nações (em sentido macro) podem ser comparados tomando-se como objeto de análise, entre outras variáveis, decisões estratégicas de coordenação e relacionadas aos limites de eficiência das firmas.

As economias liberais e as economias coordenadas de mercado caracterizariam dois tipos distintos de arranjos institucionais. No caso específico das economias liberais de mercado, um dos aspectos distintivos mais importantes está exatamente na maneira como as empresas buscam coordenar suas atividades econômicas, seja por meio de arranjos competitivos de mercado, seja utilizando o recurso da verticalização, isto é, da hierarquia (Williamson, 1975). Hall e Soskice (2001) reiteram que os relacionamentos de mercado nesse tipo de economia são caracterizados por transações de bens e serviços em regimes arm's length, em um contexto de competição e contratação formal.

\section{Regime arm's length}

No regime arm's length não existem incentivos econômicos ou organizacionais suficientes para que a confiança entre os agentes econômicos possa ser incrementada em uma base contínua, sustentada ao longo do tempo. Ao contrário, as formas frágeis de confiança, segundo terminologia proposta por Ring (1997), seriam suficientes para viabilizar transações de bens e serviços entre as empresas, mas sempre de forma limitada. Nesse caso, a confiança é meramente instrumental, cumprindo apenas o papel de simplificação das relações econômicas. Geralmente acompanhada por mecanismos mais formalizados de salvaguardas, essa base precária de confiança associa-se ao arquétipo das formas e relações puras do mercado.

A gestão de fornecedores em um regime arm's length foi dominante nos Estados Unidos e em muitos países do continente europeu por muitas décadas ao longo do século XX, até que o paradigma da produção enxuta, adotado primeiro pelas corporações japonesas, fosse transposto com sucesso também para aqueles países (Womack, Jones e Roos, 1992). O regime arm's length caracteriza-se pela tentativa dos agentes contratantes de minimizar ao máximo sua dependência em relação aos fornecedores, aumentando seu poder de negociar preços ou outras condições do fornecimento. Esse poder tende a ser mais forte quanto maior for o número de fornecedores disponíveis, obviamente, e o fato de os pedidos serem divididos entre um número maior de fornecedores facilita o poder de barganha da empresa principal, gerando uma intensa competição entre os contratados.

Nesse tipo de segmentação, os objetivos do relacionamento voltam-se mais para questões de eficiência do que para economias de aprendizagem e, talvez por isso mesmo, os contratos tendem ao curto prazo e a um elevado nível de especificações. Geralmente, em um regime arm's length, o envolvimento dos fornecedores não é antecipado no processo de suprimento e são menores a freqüência e o conteúdo da troca de informações entre os agentes, em função do baixo valor agregado ou do baixo conteúdo tecnológico dos bens transacionados, ou naquelas situações em que as compras referem-se a materiais indiretos, como por exemplo, de consumo administrativo.

\section{Regime de parceria}

O regime de parceria apresenta seguramente outras características e motivações, fundamentalmente diferentes das características e motivações presentes no arquétipo do regime arm's length.

A segmentação de fornecedores em regime de parceria parece ter sido decisiva no Japão do pós-guerra, tendo sido impulsionado um modelo de gestão particular para o relacionamento interorganizacional e a gestão das cadeias de suprimento, modelo este em grande parte sustentado por práticas colaborativas no tocante à integração de processos produtivos e logísticos entre as empresas, o que de fato impulsionou a maior especialização da economia e das empresas.

Muitos fatores concorrem para explicar a proeminência do regime partner supplier no Japão naquele período e também ajudam nessa explicação, tais como os arranjos institucionais e econômicos específicos como os keiretsus horizontais e verticais -, a escolha de uma política industrial mais adequada ao fomento da cooperação entre os agentes econômicos e a criação de um sistema particular de relações industriais. 
As primeiras lições colhidas com o exemplo japonês evidenciaram que o incremento da cooperação e a especialização de competências entre contratantes e contratadas constituíam um elemento-chave para explicar o avanço da filosofia da qualidade total e da produção enxuta em muitas corporações japonesas. Com o tempo, e a história testemunhou bem isso, também as corporações norte-americanas e européias renderam-se às vantagens de tal filosofia (Womack, Jones e Roos, 1992).

Sturgeon (2000) tem opinião alinhada com essa premissa e indica que algumas das vantagens resultantes da adoção desse regime são muito evidentes. Uma vantagem importante está na maior eficiência obtida relativamente à alocação de recursos tangíveis e intangíveis nos processos de produção e inovação, eficiência esta estimulada pela própria intensificação da desverticalização produtiva, pela especialização de competências e pela necessidade de contínuos upgrades tecnológicos nas operações dos fornecedores. Duas outras vantagens citadas por Sturgeon (2000) estão inter-relacionadas. Dizem respeito, em primeiro lugar, à melhoria da coordenação dos fluxos de informações e de recursos entre os agentes econômicos, viabilizando a prática just in time ao longo das cadeias produtivas, preferencialmente estruturadas em bases locais. Dizem igualmente respeito à superior flexibilidade do sistema - quantitativa e qualitativa - necessária para que as empresas e as cadeias de suprimento possam acomodar a volatilidade dos mercados e os problemas resultantes da maior elasticidade da demanda e mudanças contínuas nas especificações dos produtos nos mercados globalizados.

Além da produção enxuta, Sturgeon (2000) também cita os regimes de parceria como característicos à configuração das redes de produção. Além da desverticalização e da maior especialização dos agentes, essa configuração em rede envolve também a característica fundamental de proximidade espacial entre os agentes econômicos, daí o fato de o autor se referir a esses arranjos como aglomerações e estruturas produtivas em bases locais. Tais aglomerações podem ser mais ou menos organizadas.

Exemplos bem-sucedidos de redes organizadas em bases locais podem ser encontrados nas experiências dos distritos industriais localizados no centro, norte e nordeste da Itália (Brusco, 1989; Piore e Sabel, 1984; Cossentino, Pyke e Sengenberger, 1996; Lipparini, 1995; Boari, 2000); nas redes regionais de fornecimento de muitos setores em Baden-Wurttemberg, na Ale- manha (Katzenstein, 1989; Herrigel, 1993); nos clusters de informática em Bangalore, na Índia, ou do Vale do Silício, nos Estados Unidos; e nos arranjos produtivos de frutas e vinhos no Chile.

No Brasil, existem inúmeros exemplos possíveis de arranjos produtivos em bases locais (alguns caminhando para um estágio de maturidade típica de um cluster): os clusters de móveis, coureiro-calçadista e fumageiro no Rio Grande do Sul; os arranjos produtivos locais de cerâmica e têxteis em Santa Catarina; e o cluster de biotecnologia em Minas Gerais, entre outros exemplos. Todas essas experiências estão sustentadas pelo mínimo interesse em forjar relacionamentos colaborativos que possuem, entre outros, um objetivo comum: incrementar a competitividade regional e das empresas em bases locais, visando à criação de ambientes mais eficientes para os processos de inovação e produção, favorecendo assim o desenvolvimento de cadeias produtivas mais organizadas e com maior diferencial competitivo.

Comparadas ao modelo arm's length (mercado), a segmentação em regime de parceria difere por várias razões: 1) a redução drástica do número de fornecedores e a instituição de contratos de mais longo prazo; 2) o fluxo robusto de informações estratégicas e a melhor coordenação interorganizacional; 3) os incentivos para incremento dos investimentos em ativos específicos do tipo geográfico (plantas focalizadas), físico (máquinas, dispositivos, ferramental), humano (por exemplo, um operador de um fornecedor trabalhando internamente em alguma função específica na linha de montagem da contratante); 4) os níveis superiores de serviços em âmbito logístico; 5) a velocidade no desenvolvimento de novos produtos; 6) as relações de cooperação e confiança sustentadas por estruturas e mecanismos de governança capazes de conter práticas oportunistas e, simultaneamente, reduzir os custos de transações entre as firmas.

Em um regime de efetiva parceria entre as empresas, o conteúdo das transações tende a ser mais complexo, e os meios utilizados para a troca de informações e para a comunicação bilateral entre os agentes são mais articulados (Sobrero, 1996). Com empresas parceiras, os processos de aprendizagem ou o desenvolvimento de competências particulares costumam ser mais proeminentes que objetivos exclusivos de eficiência no tocante a custos.

Um outro aspecto importante dos relacionamentos entre empresas parceiras é que os contratos tendem a ser mais flexíveis ou a apresentar um nível menor de 
especificações, o que ocorre sobretudo quando o objeto da transação envolve conteúdos complexos. Um exemplo é a participação do fornecedor nos processos de P\&D da empresa cliente, o que poderia concretizar seu ingresso antecipado na relação de fornecimento (Clark e Fujimoto, 1992; Lamming, 1993). Já o contrário mostra-se típico às estruturas de relacionamento em regime arm's length, em que o conteúdo do objeto da transação tende a ser mais simples, não-customizado ou contendo menor valor agregado: os contratos tendem ao curto prazo e a um nível maior de especificações, sobretudo de natureza técnica, indicando o que deve ser feito e quais os parâmetros mínimos de desempenho e confiabilidade na fabricação que deverão ser respeitados.

\section{Regime de quase-mercado}

Seguindo a taxonomia proposta por Dyer, Cho e Chu (1998), tem-se uma terceira forma de segmentação, identificada como regime de quase-mercado. Com o avanço das formas em rede, além dos regimes de parcerias, observa-se a emergência de estruturas de governança e relacionamentos mais duradouros entre empresas, mesmo no caso de transações e contratos considerados não-estratégicos. Alguns componentes são assim chamados porque, embora representem inputs absolutamente necessários à produção da contratante, podem não ser considerados estratégicos por alguns motivos: por não envolverem ativos específicos; por serem de menor valor agregado; por não interferirem diretamente nos processos e nas competências centrais da organização cliente; ou por serem materiais de uso indireto (não-consumidos diretamente na produção).

A tendência observada nos últimos anos, em diferentes países e empresas, é que as estratégias de segmentação em regime de quase-mercado estão substituindo, pouco a pouco, os regimes antes regulados exclusivamente pela perspectiva arm's length. Isso vem ocorrendo porque as empresas passam a reconhecer duas importantes conseqüências das estruturas de relacionamento reguladas pelo regime de quase mercado. Em primeiro lugar, que os custos administrativos e de transação envolvidos na gestão de um número muito grande de fornecedores geralmente ultrapassam os benefícios decorrentes da redução de custos gerados por essa política. Para certos tipos de contratos, há maior eficiência, qualidade e produtividade no fornecimento se são reduzidos progressivamente os pontos de origem no sistema logístico. Além disso, ao se dividirem as compras por um número muito elevado de fornecedores, é possível uma perda de economia e de ganhos de escala por parte dessas empresas, aumentando o preço do que se transaciona. No entanto, um segundo ponto importante dessa transição está no reconhecimento de que a seleção de um número restrito de fornecedores, competentes e capacitados - duas ou três empresas, por exemplo - já seria suficiente para manter uma intensa competição entre os fornecedores, no sentido de que se esforcem por garantir um desempenho em preço e qualidade suficientemente fortes para sustentar a renovação dos contratos ao longo do tempo.

Um importante aspecto das estratégias de outsourcing relativas aos regimes de segmentação, especialmente ao regime arm's length, de um lado, e aos regimes de parceria e quase-mercado, de outro, refere-se à questão dos investimentos em ativos específicos na transação. Por lógica, parece ser uma missão impossível para a gerência logística buscar a integração sistêmica de seus processos com fornecedores e clientes em um cenário de baixa intensidade de investimentos em ativos específicos ou de ausência de tais investimentos.

Sobre esse importante aspecto das relações interorganizacionais, a partir de uma pesquisa que se tornou bastante conhecida, Dyer (1997) comparou as relações de fornecimento entre montadoras japonesas e norteamericanas, demonstrando que, apesar de os investimentos em ativos específicos serem mais intensos no caso das cadeias de suprimento de empresas nipônicas, estas experimentavam custos de transação menores quando comparados aos de suas concorrentes norteamericanas. Para uma das empresas japonesas estudadas na pesquisa, a montadora que possuía o maior número de fornecedores especializados - caso da Toyota - também se beneficiou com menores custos de transação comparativamente à Nissan, que, por sua vez, mantinha um número menor de fornecedores especializados.

No que se refere às diferenças percebidas entre os casos norte-americano e japonês, os resultados da pesquisa de Dyer (1997) poderiam ser contestados, argumentando-se que fatores legais ou institucionais, bem como a natureza do controle e das sanções previstas em lei, poderiam estar influenciando a intensidade do comportamento oportunista dos agentes. Seria legítimo pensar, nesse caso, que os investimentos em ativos específicos são mais intensos e os custos de transação são menores para uma empresa como a Toyota, em virtude, por exemplo, do ambiente institucional japonês, em que o papel das estruturas de keiretsus na 
articulação de cadeias produtivas não poderia ser desprezado. Entretanto, tal justificativa talvez sirva mais à especulação do que propriamente para esclarecer o conteúdo e a direção dos resultados da pesquisa.

Tome-se, por exemplo, o caso norte-americano, comparando-se a GM e a Chrysler. À época da pesquisa, à GM interessava pulverizar seus pedidos de compras entre um número mais amplo de fornecedores, inclinando-se mais ao regime de tipo arm's length. À Chrysler, por sua vez, interessava estabelecer regimes de parceria com seus fornecedores mais importantes. Ambas atuavam constrangidas por um mesmo "ambiente institucional" e, no entanto, apresentaram custos de transação diferentes, sugerindo que o peso do ambiente institucional não pode ser considerado como decisivo ou determinante dos custos de transação. Assim, quais motivos teriam levado os custos de transação das montadoras japonesas a serem significativamente menores comparando-se os custos de transação das firmas ocidentais?

Cinco fatores explicam esse resultado, segundo os resultados da pesquisa de Dyer (1997):

- transações recorrentes com um número mais restrito de fornecedores preferenciais teriam o potencial de reduzir os custos e o risco de comportamentos oportunistas entre os agentes, uma vez que, quanto mais significativos são os volumes das trocas e as expectativas de vigência dos contratos, teoricamente são maiores a rentabilidade e a relevância do negócio para as duas partes;

- as economias de escala nas relações de suprimento fazem com que as empresas consigam trabalhar com um conjunto mais previsível de informações sobre produtos e mercados com seus fornecedores, o que pode gerar um efeito sensível na redução dos custos ex ante e ex post dos contratos;

- o maior compartilhamento de informações estratégicas e a melhoria da confiabilidade e da robustez do fluxo informacional com fornecedores e clientes podem tornar menores as assimetrias de informação entre os agentes, definindo uma vantagem competitiva fundamental em várias frentes, como nos processos de inovação e na coordenação logística;

- mecanismos alternativos para o controle do oportunismo podem estar orientados para conter potenciais problemas relativos aos investimentos em ativos específicos na relação, tais como a propriedade cruzada de ações, uma política clara de compartilhamento de lucros operacionais ou a edificação de formas menos frágeis de confiança entre os atores, a partir de contratos de longo prazo, por exemplo;
- com o passar do tempo, e com a amortização dos primeiros investimentos e o bom histórico do relacionamento, o clima de confiança entre as partes pode efetivamente crescer, favorecendo a trajetória de redução dos custos de transação enquanto, simultaneamente, há a impulsão de economias de escala e aprendizagem entre as empresas.

\section{Segmentação de fornecedores nos processos de inovação}

Além dos custos de transação relativos às atividades de produção, não há sentido desprezar a importância do relacionamento interorganizacional também nas atividades de inovação. A perspectiva da segmentação aplicada às atividades de inovação encontra respaldo em muitos trabalhos (Clark e Fujimoto, 1992; Lamming, 1993; Kamath e Liker, 1994; Calabrese, 1999; Womack, Jones e Roos, 1992), entre outros.

Tal questão é até certo ponto bastante coerente, especialmente pelo fato de que a desverticalização produtiva veio acompanhada nas empresas, em muitos casos, pela desintegração vertical progressiva também das atividades de inovação, exigindo das organizações uma participação crescente em processos conjuntos de P\&D e em alianças estratégicas orientadas para a redução do lead time da inovação, para as práticas de produção conjunta (co-makership) e para o compartilhamento de informações relativas aos produtos e à demanda.

Algumas variáveis críticas para a definição dos regimes de segmentação de fornecedores nos processos de inovação estão resumidas no Quadro 1 , adiante.

Existem suportes diretos e indiretos segundo as diretrizes esboçadas pelas estratégias de segmentação de fornecedores nos processos de inovação. Como suporte direto às atividades inovativas do fornecedor, tem-se um conjunto de processos que podem ir desde a formação de pessoal técnico na sede da empresa cliente e de visitas permanentes de técnicos às instalações das empresas fornecedoras até o destacamento de grupos específicos de trabalho e ajuda técnica e financeira para os novos investimentos a serem realizados pela parte contratada. Como suporte indireto aos processos de inovação, as empresas clientes podem oferecer sugestões para a adoção de novas tecnologias, para a redução de custos do fornecedor e também para mudanças que visem à melhoria da qualidade e da coordenação logística da empresa fornecedora.

Maior intensidade em um ou outro tipo de suporte (direto ou indireto) aos processos de inovação parece 
variar em função da capacidade tecnológica do fornecedor e de quão críticos se revelam os inputs da transação diante do conjunto de competências centrais da empresa cliente. Por isso é que, quanto mais sólida e robusta for a aliança estratégica entre empresas clientes e fornecedoras, tanto maiores as probabilidades de ocorrência de suportes diretos por parte das contratantes. Igualmente, quanto menos críticos os inputs e menos estratégica a vinculação entre fornecedor e cliente, tanto mais o suporte oferecido às atividades inovativas tenderá a ser indireto.

A necessidade de impulsionar uma estrutura de coordenação interorganizacional mais eficiente entre clientes e fornecedores vem determinada, segundo Kamath e Liker (1994), por características afins ao relacionamento, ao objeto da transação e à capacidade tecnológica dos atores. Entre esses elementos, destacam-se: a intensidade e a complexidade dos fluxos de informação e de recursos entre os agentes econômicos; a natureza do objeto da transação; o nível de investimentos em ativos; a capacidade tecnológica do fornecedor e sua influência nas especificações do design do produto da empresa cliente; o nível de complementaridade dos recursos e de competências entre as empresas; o momento de envolvimento do fornecedor no processo de suprimento; e a responsabilidade pelo design, entre outros fatores (Ebers, 1997; Lorenzoni e Lipparini, 1999; Sobrero, 1996).
A direção dos resultados das estratégias de segmentação de fornecedores nos processos de produção e de inovação parece ser coerente com os esforços despendidos por empresas fornecedoras para a dinamização de suas próprias estratégias de segmentação concernentes à gestão de clientes. Esses dois esforços, orientados por processos mais exclusivos de segmentação de fornecedores, por um lado, e pela segmentação de clientes, por outro, parecem contribuir decisivamente para as empresas no tocante à impulsão de comportamentos mais colaborativos ao longo das cadeias de suprimento. Benefícios importantes surgem da colaboração direta dos fornecedores com seus clientes no que se refere aos processos ligados à produção e à logística, bem como a funções exclusivamente mercadológicas. O conteúdo da próxima seção do trabalho explora, assim, o problema da colaboração, considerando, dessa vez, as estratégias de segmentação de clientes e os aspectos importantes concernentes à filosofia do marketing de relacionamento.

\section{Segmentação de clientes}

As estratégias de segmentação de clientes possuem como objetivo mercadológico, para as empresas fornecedoras, a oferta permanente de produtos e serviços projetados sob medida (customizados) de modo a satisfazer às necessidades específicas dos clientes atendidos. Tendo como objetivo a coordenação do relacionamento com esses

Quadro 1 - Regimes de segmentação de fornecedores nos processos de inovação.

\begin{tabular}{|c|c|c|c|c|}
\hline CARACTERÍSTICAS REGIME & PARCERIA ESTRATÉGICA & PARCERIA & QUASE-MERCADO & MERCADO \\
\hline $\begin{array}{l}\text { Responsabilidade } \\
\text { pelo design }\end{array}$ & Fornecedor & Fornecedor & Co-design & Cliente \\
\hline $\begin{array}{l}\text { Complexidade } \\
\text { do produto }\end{array}$ & Sistema & $\begin{array}{l}\text { Subsistemas; } \\
\text { montagens complexas }\end{array}$ & $\begin{array}{l}\text { Subsistemas; } \\
\text { montagens simples }\end{array}$ & Partes simples \\
\hline $\begin{array}{l}\text { Provisão de } \\
\text { especificação }\end{array}$ & Conceito do produto & Especificações críticas & $\begin{array}{l}\text { Especificações para } \\
\text { o fornecedor }\end{array}$ & $\begin{array}{l}\text { Design para } \\
\text { o fornecedor }\end{array}$ \\
\hline $\begin{array}{l}\text { Momento de } \\
\text { envolvimento do } \\
\text { fornecedor }\end{array}$ & Antecipado & Antecipado & $\begin{array}{l}\text { Após o desenvolvimento do } \\
\text { conceito de produto e da } \\
\text { fase de prototipagem }\end{array}$ & Protótipo \\
\hline $\begin{array}{l}\text { Responsabilidade pelo } \\
\text { teste de componentes }\end{array}$ & Total & Total & Moderada & Menor \\
\hline $\begin{array}{l}\text { Capacidade tecnológica } \\
\text { do fornecedor }\end{array}$ & Autônomo & Alta & Mediana & Baixa \\
\hline
\end{tabular}

Fonte: Kamath e Liker (1994, p. 162). 
clientes, muitas empresas fornecedoras de grande porte instituíram, nas últimas décadas, equipes de profissionais especializados em tal função, quase sempre gerenciados pela figura profissional de um key account manager (gestor de clientes estratégicos).

Os processos e atividades relacionados à função do key account manager representam uma conseqüência natural da decisiva orientação da empresa fornecedora ao cliente e ao marketing de relacionamento nos mercados intermediários (Donald e Rogers, 1999). Dito de outra forma, na gestão de contas especiais, a palavra de ordem é o marketing de relacionamento. As atividades do marketing, integradas aos esforços da logística, por estarem orientadas para as demandas de produtos e serviços dos clientes, mostram-se fundamentais à construção de relacionamentos sempre mais duradouros, uma vez que, para o fornecedor, é naturalmente mais difícil e custoso obter novos clientes do que se esforçar para garantir a continuidade e a ampliação dos negócios com um grupo específico de clientes estratégicos.

A recente evolução do conceito da logística evidencia a necessidade de que as decisões de produção e vendas nas empresas sejam orientadas pelo comportamento de compra dos clientes intermediários e finais. Esse parece ser exatamente um dos pilares ou uma das condições específicas para impulsionar práticas de marketing de relacionamento nos mercados intermediários. A orientação fundamental passa a ser, assim, a customização dos produtos e dos serviços às necessidades percebidas pelos clientes, bem como a eliminação das atividades que a eles e à empresa pareçam não agregar valor.

Pelo lado da empresa fornecedora, a definição de critérios para a avaliação quanto à importância estratégica de cada um de seus clientes (por exemplo, volumes transacionados ou valor da venda) favorece, em uma etapa subseqüente, sua entrada em circuitos relacionais mais densos com esses mesmos clientes. Certamente, essa é uma estratégia que requer longo prazo para amadurecer e dar frutos, uma vez que muitos anos podem ser necessários desde o momento em que se identifica a atratividade de um cliente até o momento de viabilizar, com ele, um relacionamento mais rentável e promissor.

As fases do key account management podem ser definidas tomando-se como base o cruzamento de duas variáveis: o nível de envolvimento da fornecedora com a empresa cliente e a natureza do relacionamento (Donald e Rogers, 1999). Existem cinco fases fundamentais nos processos relativos à gestão de clientes estratégicos. Essas fases estão dispostas na Figura 1 e serão brevemente comentadas a seguir.

Figura 1 - As fases do key account management.

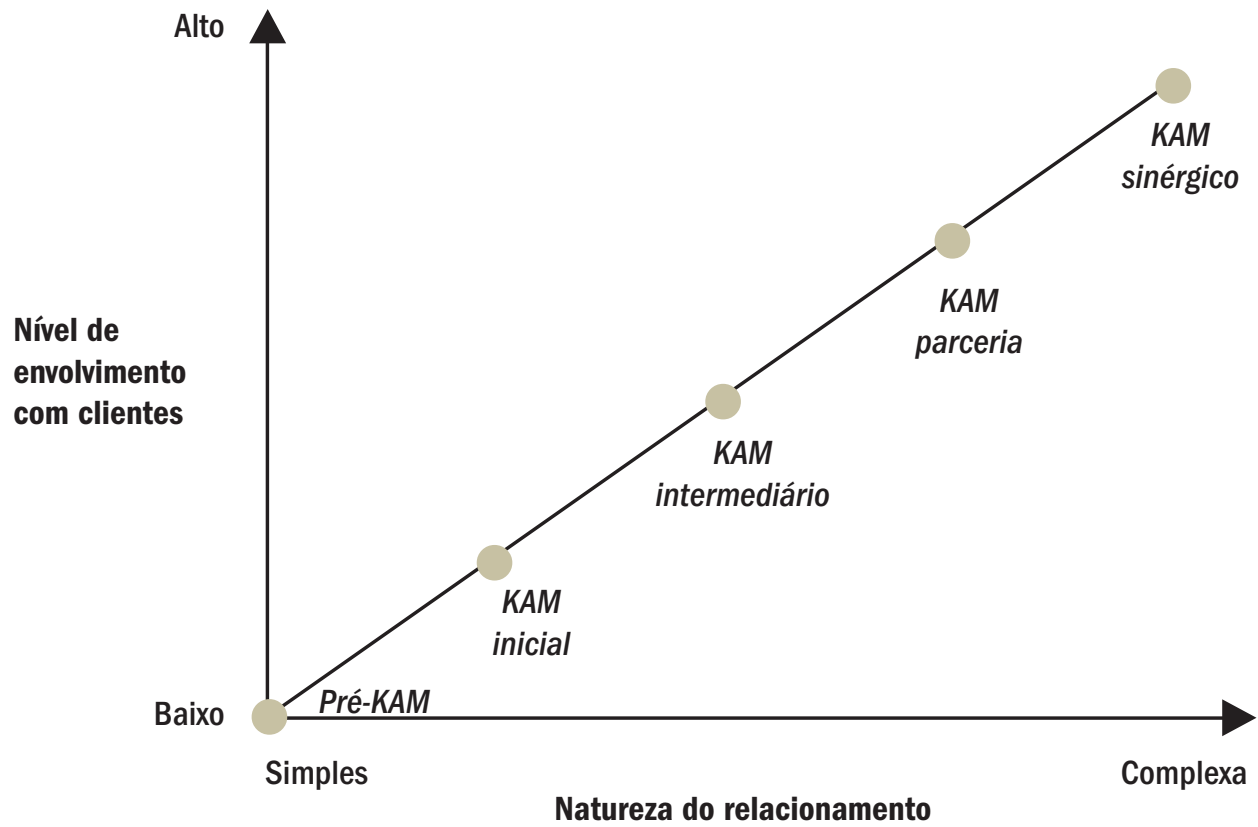

Fonte: Donald e Rogers (1999, p. 30). 
A fase do Pré-KAM envolve apenas o interesse do fornecedor em se aproximar de um cliente potencial, já que não existem transações em curso e a cota de negócios no portfólio da fornecedora é zero. Caso venha a ser bem-sucedida essa aproximação com clientes potenciais, muito provavelmente a empresa fornecedora terá de passar por um período muito duro de auditorias e testes com a finalidade de atestar sua competência, seus atributos e vantagens competitivas à empresa cliente.

A fase subseqüente ao Pré-KAM é a do KAM-inicial, implicando efetivamente transações de compra e venda de produtos e/ou serviços entre as partes. Naturalmente, por conta do pouco tempo de relacionamento, o fornecedor chegará apenas a deter uma cota marginal do negócio da empresa cliente, sendo muito provável que esse cliente mantenha com tal fornecedor uma relação de suprimento regulada pelos mecanismos de mercado, isto é, em regime arm's length. Mesmo assim, caso o fornecedor anteveja o potencial de crescimento do relacionamento, seus esforços devem estar orientados obrigatoriamente à ampliação dessa participação, assegurando vantagens competitivas em relação a custo, qualidade, velocidade, confiabilidade e níveis de serviços.

A fase intermediária e a fase de parceria no key account management representam um progresso no âmbito das estruturas de relacionamento. No caso do KAM-intermediário, a fornecedora opera como contratada preferencial da empresa cliente, mantendo com esta uma interação mais complexa. O fornecedor percebe a importância do cliente para seu negócio e procura evidentemente todos os meios de conhecer melhor as necessidades específicas da contratante. Tratase de uma fase bastante delicada para o fornecedor, considerando-se aqui o fato de que ele não experimentará ainda uma situação de exclusividade no atendimento das demandas da empresa cliente, mas deverá se esforçar ao máximo (eventualmente até mesmo perdendo parte do lucro em suas operações) para incrementar sua participação nos negócios com a contratante.

Estruturas especializadas de governança provavelmente ocorrerão somente com a segmentação em regime de parceria, em que a fornecedora não é mais apenas uma entre outras contratadas, mas representa um recurso externo estratégico na perspectiva da própria empresa cliente. Com a parceria, a cota dos negócios pode chegar muitas vezes a $100 \%$, e novos mecanismos de governança deverão surgir como suporte ao incremento do fluxo informacional e de recursos entre as duas partes.
Diferentemente do que acontece nas fases anteriores, o regime de parceria no tocante aos processos de key account management exige a convergência dos planejamentos estratégicos das duas empresas, sendo maior a responsabilidade destas em garantir a continuidade do relacionamento, considerando-se a intensidade de investimentos em ativos específicos na transação e a complementaridade de processos e recursos das duas organizações. Esforços mútuos são envidados pelas partes visando à melhoria progressiva dos serviços, ao aumento da qualidade, à redução progressiva dos custos e ao compartilhamento dos lucros. Com o tempo, essa aproximação pode vir a resultar em uma alteração do próprio conteúdo do fluxo informacional e da conduta estratégica da empresa fornecedora, já que suas decisões e seu comportamento exercerão impactos diretos em atividades críticas da contratante.

A última fase do processo de gestão de clientes estratégicos caracteriza-se pela completa integração e sinergia em todos os processos envolvidos no outsourcing, não restando nem mesmo demarcadas as estruturas organizacionais das empresas. Com o KAMsinérgico, esperam-se interfaces em todos os níveis, funções e processos das duas organizações. Do ponto de vista das formas organizacionais, pode-se pensar aqui em uma estrutura de quase-integração, em que planos de negócios, estratégias, pesquisas de mercado e desenvolvimento de produtos são realizados de forma conjunta pelas empresas fornecedora e cliente. Nessa última fase, portanto, o fornecedor direciona todos os seus recursos para atender de forma customizada às necessidades dos seus clientes estratégicos, buscando integrar os fluxos de informação e os processos de decisão em todos os níveis de sua estrutura.

As práticas de segmentação de fornecedores a partir dos regimes arm's length, quase-mercado e parceria são aderentes aos procedimentos e etapas concernentes à evolução dos processos de segmentação de clientes. Para uma contratante, por exemplo, a adoção de uma estratégia de segmentação de fornecedores em regime arm's length não terá a contrapartida, por parte do fornecedor, de um esforço adicional deste no sentido de garantir uma posição de sinergia ou de absoluta integração de seus processos com essa empresa cliente. Entretanto, se por razões tecnológicas ou por uma competência distintiva do fornecedor a empresa cliente decidir-se por uma aliança estratégica com tal fornecedor, a probabilidade de que este se interesse por manter e ampliar suas bases de relacionamento com essa contratante será significativamente ampliada, sobretudo se estiver em 
jogo a negociação de uma política de suprimento exclusiva com tal fornecedor no futuro.

A segmentação de fornecedores e de clientes em pontos específicos da cadeia de valor representa uma prática gerencial que pode ser ampliada para garantir objetivos de maior desempenho de redes inteiras de suprimento. Dessa forma, o esforço individual das empresas, orientado para a segmentação de sua base de fornecedores e para a segmentação da oferta de produtos e serviços a diferentes grupos de clientes diretos, representaria, na verdade, dois lados de um mesmo objetivo: a criação de valor ao longo da cadeia e a apropriação desse valor pelos clientes finais, com a possibilidade de custos controlados e de elevados padrões de customização da oferta.

\section{CONCLUSÕES}

Este artigo procurou demonstrar de que forma as estratégias de segmentação de fornecedores e clientes são úteis para o alinhamento das decisões operacionais entre as empresas, especialmente para a integração de processos logísticos no contexto mais amplo das cadeias de suprimento. Entre outros pontos, defendeuse a idéia de que em um contexto competitivo como o atual, caracterizado por uma intensa desverticalização das atividades de produção e de inovação e pela elevada volatilidade e complexidade dos mercados, as empresas estão atentas aos benefícios potenciais do gerenciamento estratégico de suas práticas de outsourcing com fornecedores e às vantagens evidentes de uma gestão proativa no que se refere ao marketing de relacionamento com seus diferentes segmentos de clientes diretos.

Referências também foram feitas, neste artigo, à evolução dos regimes de segmentação de fornecedores no âmbito das práticas de supply chain management. Ressaltou-se a migração das relações de mercado para relações de quase-mercado - em geral para suprimentos considerados não-estratégicos, para materiais indiretos ou de menor valor agregado para a contratante - ou para regimes de parceria com fornecedores de inputs considerados estratégicos, seja por conta de seu valor agregado, seja por sua importância para os processos de manufatura e de inovação das empresas clientes. A recente valorização dos regimes de quase-mercado e de parceria retrata, em certa medida, um esgotamento das formas clássicas de contratação (arm's length) na gestão dos processos de suprimento e, por extensão, dos vínculos de relacionamento no que se refere à distribuição física dos produtos para os mercados finais.

A partir das questões teóricas levantadas neste trabalho, algumas questões poderiam orientar a direção de futuras pesquisas sobre o tema abordado:

- Em que nível o histórico e a maior estabilidade dos vínculos de relacionamento entre as empresas facilitam as economias de escala e de aprendizagem? Quais os impactos sobre a natureza dos contratos e sobre a dinâmica interorganizacional? Quais os impactos sobre os serviços do ponto de vista da logística?

- Nas atuais estratégias de suprimento das empresas industriais, confirma-se ou não a tendência de serem edificadas estruturas de quase-mercado na regulação das transações para inputs de menor valor agregado ou indiretos às necessidades da produção?

- De que maneira os processos de desverticalização produtiva afetam a transferência dos custos de transação na cadeia logística? É possível mensurar os impactos de tais processos sobre os níveis de colaboração na cadeia de suprimentos?

- Os novos arranjos produtivos consolidados no Brasil e no mundo (como os condomínios industriais, por exemplo), ao exercerem um impacto sensível sobre fluxo de informações e de recursos nos vínculos com fornecedores a montante na cadeia de produção, favorecem quais aspectos da colaboração entre os agentes?

As respostas para algumas dessas questões podem corroborar a existência, hoje, de uma necessidade premente na agenda das empresas: manter o foco no negócio principal, aumentar a lucratividade dos negócios - a partir da decisão pela desintegração vertical de parte ou da totalidade das atividades de produção e inovação - e, simultaneamente, favorecer o valor percebido pelos clientes intermediários e finais, além de outros stakeholders interessados (acionistas, fornecedores e trabalhadores, entre outros). Tal medida constitui um passo decisivo para tornar as empresas mais flexíveis e mais bem preparadas a atuar em um contexto de competição entre cadeias de suprimento, mas representa também o risco de se definir uma clivagem insuperável para empresas menos preparadas para atuar em mercados mais difíceis, instáveis e turbulentos.

Este trabalho procurou identificar oportunidades para uma gestão efetivamente integrada da cadeia de suprimentos, o que requer a especialização de funções em contextos locais e o planejamento colaborativo entre pequenas, médias e grandes empresas, em dife- 
rentes ciclos dos processos de suprimento, de produção e de distribuição física. As estratégias de segmentação com fornecedores e clientes representam, assim, um caminho para a construção de ambientes verdadeiramente mais colaborativos para as transações entre as empresas, condição essencial em um cenário de intensa desverticalização e especialização de funções. Quanto maior a exigência de especialização de funções em uma rede de suprimentos, tanto mais premente a necessidade de se ter o alinhamento das decisões logísticas entre um número maior de agentes, capaz de orientar o planejamento colaborativo relativo a fluxos de materiais, informações, propriedades, riscos e meios de pagamento ao longo das várias etapas da cadeia de valor.

\section{Artigo recebido em 13.09.2003. Aprovado em 09.01.2004}

\section{Referências bibliográficas}

ANDERSON, E.; GATIGNON, H. Modes of foreign entry: a transaction cost analysis and propositions. Journal of International Business Studies, v. 17, n. 3, p. 1-26, 1986.

ASTLEY, W. G. Toward an appreciation of collective strategy. Academy of Management Review, v. 9, n. 3, p. 526-535, 1984.

BOARI, C. Industrial clusters and SMEs development: an Italian perspective. In: WORLD BANK WORKSHOP ON SMALL AND MEDIUM ENTERPRISES, 1999, Thailand. Proceedings... Thailand, 2000.

BOWERSOX, D. J. et al. Logistical excellence. Burlington: Digital Press, 1992.

BROWN, J. E.; HENDRY, C. Industrial districts and supply chains as vehicles for managerial and organizational learning. International Studies in Management and Organization, v. 27, n. 4, p. 127-157, 1998.

BRUSCO, S. Piccole imprese e distretti industriali. Torino: Rosenberg \& Sellier, 1989.

BUCKLEY, P. J.; CASSON, M. A theory of cooperation in international business. In: CONTRACTOR, F. J.; LORANGE, P. (Eds.). Cooperative strategies in international business. Lexington, MA: Lexington Books, 1988.

CALABRESE, G. Fare auto: la comunicazione e la cooperazione nel processo di sviluppo prodotto. Torino: CNR/CERIS, 1999.

CHRISTOPHER, M. Logística e gerenciamento da cadeia de suprimentos: estratégias para a redução de custos e melhoria dos serviços. São Paulo: Pioneira, 1997.

CLARK, K. B.; FUJIMOTO, T. Product development performance: strategy, organization and management. Boston: Harvard Business School Press, 1992
CONTRACTOR, F. J.; LORANGE, P. (Eds.) Cooperative strategies in international business. Lexington, MA: Lexington Books, 1988.

COOKE, P.; MORGAN, K. The associational economy: firms, regions and innovation. New York: Oxford University Press, 1998.

COSSENTINO, F; PYKE, F; SENGENBERGER, W. Le risposte locali e regionali alla pressione globale: il caso dell'Italia e dei suoi distretti industriali. Bologna: Il Mulino, 1996.

Di MAGGIO, P.; POWELL, W. The iron cage revisited: institutional isomorphism and collective rationality in organizational fields. American Sociological Review, v. 48, n. 2, p. 147-160, 1983.

DONALD, M.; ROGERS, B. La gestione dei clienti strategic. Milano: Franco Angeli, 1999

DOZ, Y. The evolution of cooperation in strategic alliances: initial conditions or learning process? Strategic Management Journal, v. 17, Special Issue, p. $55-83,1996$

DUBOIS, A.; HAKANSSON, H. Relationships as activity links. In: EBERS, M. (Ed.). The formation of inter-organizational networks. New York: Oxford University Press, 1997. p. 43-65.

DYER, J. Effective interfirm collaboration: how firms minimize transaction costs and maximize transaction value. Strategic Management Journal, v. 18, n. 7, p. 535-556, 1997.

DYER, J.; CHO, D. S.; CHU, W. Strategic supplier segmentation: the next best practice in supply chain management. California Management Review, v. 40, n. 2 , p. $57-77,1998$.

EBERS, M. Explaining inter-organizational network formation. In: EBERS, M. (Ed.). The formation of inter-organizational networks. New York: Oxford University Press, 1997. p. 1-40.

EBERS, M.; JARILLO, J.C. The construction, forms and consequences of industry network. International Studies in Management and Organizations, v. 27, n. 4, p. 3-21, 1998.

FERROZI, C.; HAMMOND, J.; SHAPIRO, R. D. Logística e estratégia. Torino: GEA/ISEDI, 1993.

FLEURY, P. F. Conceito de logística integrada e supply chain management. In: FLEURY, P. F; WANKE, P.; FIGUEIREDO, K. F. (Orgs). Logística empresarial: a perspectiva brasileira. São Paulo: Atlas, 2000. p. 27-38.

GULATI, R. Alliances and networks. Strategic Management Journal, v. 19, n. 4, p. 293-317, 1998.

HALL, P. A.; SOSKICE, D. Varieties of capitalism: the institutional foundations of comparative advantage. Oxford: Oxford University Press, 2001.

HENNART, J. F. A transaction costs theory of equity joint ventures. EStrategic Management Journal, v. 9, n. 4, p. 361-374, 1988. 
HERRIGEL, G. B. Power and the redefinition of industrial districts: the case of Baden-Wurttemberg. In: GRABHER, G. (Ed.). The embedded firm: on the socioeconomics of industrial networks. London: Routledge, 1993. p. 227-251.

KAMATH, R.; LIKER, J. K. A second look at Japanese product development. Harvard Business Review, v. 72, n. 6, p. 154-169, 1994.

KATZENSTEIN, P. Industry and politics in West Germany: toward the third republic. London: Cornell University Press, 1989.

KOBAYASHI, S. Renovação da logística: como definir estratégias de distribuição física global. São Paulo: Atlas, 2000.

KOGUT, B. Joint ventures: theoretical and empirical perspectives. Strategic Management Journal, v. 9, n. 4, p. 319-322, 1988.

KOGUT, B.; SHAN, W.; WALKER, G. The make-or-cooperate decision in the context of industry network. In: NOHRIA, N.; ECCLES, R. G. (Orgs). Networks and organizations: structure, form and action. Boston: Harvard Business School Press, 1992. p. 348-365.

KOPCZAK, L. R.; JOHNSON, M. E. The supply chain management effect. Sloan Management Review, v. 44, n. 3, p. 27-34, 2003.

KOZA, M. P.; LEWIN, A. Y. The co-evolution of strategic alliances. Organization Science, v. 9, n. 3, p. 255-261, 1998.

LAMMING, R. Beyond partnership: strategies for innovation and lean supply. Hemel Hemstead: Prentice-Hall International, 1993.

LIPPARINI, A. Imprese, relazione tra imprese e posizionamento competitivo. Milano: Etaslibri, 1995.

LORENZONI, G.; LIPPARINI, A. The leveraging of interfirm relationships as a distinctive organizational capability: a longitudinal study. Strategic Management Journal, v. 20, n. 4, p. 317-338, 1999.
MÖLLERING, G. A typology of supplier relations: from determinism to pluralism in inter-firm empirical research. Journal of Purchasing \& Supply Management, v. 9, n. 1. p. 31-41, 2003.

NOHRIA, N. Is a network perspective a useful way of studying organizations? In: NOHRIA, N.; ECCLES, R. G. (Orgs). Networks and organizations: structure, form and action. Boston: Harvard Business School Press, 1992. p. 1-22.

NOVAES, A. G. Da logística ao supply chain management. In: NOVAES, A. G. (Org.). Logística e gerenciamento da cadeia de distribuição. Rio de Janeiro: Campus, 2001.

PARKHE, A. Partner nationality and the structure-performance relationship in strategic alliances. Organization Science, v. 4, n. 2, p. 301-324, 1993.

PIORE, M. J.; SABEL,C. F. The second industrial divide: possibilities for prosperity. Boston: Basic Books, 1984.

REUER, J. J.; MILLER, K. D. Agency costs and the performance implications of international joint venture internationalization. Strategic Management Journal, v. 18, n. 6, p. 425-438, 1997.

RING, P. S. Processes facilitating reliance on trust in inter-organizational networks. In: EBERS, M. (Org). The formation of inter-organizational networks. New York: Oxford University, 1997. p. 113-145.

SOBRERO, M. Innovazione tecnologica e relazioni tra imprese: teoria e prassi. Italia: Nuova Italia Scientifica, 1996

STURGEON, T. J. How do we define value chains and production networks? MIT, Industrial Performance Center (IPC). MIT Special Working Paper Series, n. 00-010, 2000.

WILLIAMSON, O. E. Markets and hierarchies: analysis and antitrust implications. New York: The Free Press, 1975.

WOMACK, J. P.; JONES, D. T.; ROOS, D. A máquina que mudou o mundo. Rio de Janeiro: Campus, 1992.

\section{Marcelo Bronzo \\ Professor Adjunto do CEPEAD/CAD/UFMG. Doutor em Administração pelo CEPEAD/UFMG. Interesses de pesquisa em gerenciamento das cadeias de suprimento, canais de marketing, estratégias de segmentação de fornecedores, relacionamentos colaborativos em atividades de produção e inovação. \\ E-mail: marcelobronzo@cepead.face.ufmg.br Endereço: Rua Curitiba, 832, sala 1009 - Centro, Belo Horizonte - MG, 30170-120.}

